\title{
Functional study on the mutations in the silkworm (Bombyx mori) acetylcholinesterase type 1 gene (ace1) and its recombinant proteins
}

\author{
Ju-mei Wang $\cdot$ Bin-bin Wang $\cdot$ Yi Xie $\cdot$ Shan-shan Sun $\cdot$ Zhi-ya Gu \\ Lie Ma $\cdot$ Fan-chi Li $\cdot$ Yi-fan Zhao $\cdot$ Bin Yang $\cdot$ Wei-de Shen $\cdot$ Bing Li
}

Received: 21 January 2013/ Accepted: 19 November 2013/Published online: 10 December 2013

(C) The Author(s) 2013. This article is published with open access at Springerlink.com

\begin{abstract}
The acetylcholinesterase of Lepidoptera insects is encoded by two genes, ace 1 and ace 2 . The expression of the ace 1 gene is significantly higher than that of the ace 2 gene, and mutations in ace 1 are one of the major reasons for pesticide resistance in insects. In order to investigate the effects of the mutations in ace 1's characteristic sites on pesticide resistance, we generated mutations for three amino acids using sitedirected mutagenesis, which were Ala(GCG)303Ser(TCG), Gly(GGA)329Ala(GCA) and Leu (TCT)554Ser(TTC). The Baculovirus expression system was used for the eukaryotic expression of the wild type ace 1 (wace 1 ) and the mutant ace 1 (mace1). SDS-PAGE and Western blotting were used to detect the targeting proteins with expected sizeof about $76 \mathrm{kDa}$. The expression products were purified for the determination of AChE activity and the inhibitory effects of physostigmine and phoxim. We observed no significant differences in the overall activity of the wild type and mutant AChEs. However, with 10 min of physostigmine $(10 \mu \mathrm{M})$ inhibition, the remaining activity of the wild type AChE was significantly lower than that of the mutant AChE. Ten min inhibition with $33.4 \mu \mathrm{M}$ phoxim
\end{abstract}

Ju-mei Wang, Bin-bin Wang and Yi Xie have contributed equally to the study.

J. Wang $\cdot$ B. Wang $\cdot$ Y. Xie $\cdot$ S. Sun $\cdot$ Z. Gu $\cdot$ L. Ma $\cdot$ F. Li $\cdot$

Y. Zhao · W. Shen $(\bowtie) \cdot$ B. Li $(\bowtie)$

School of Basic Medicine and Biological Sciences, Soochow

University, Suzhou 215123, Jiangsu, People's Republic of China

e-mail: sdlibing@hotmail.com

B. Yang

Jiangsu Minxing Cocoon Silk Stock Co., Ltd,

Dongtai 224200, Jiangsu, People's Republic of China

W. Shen · B. Li

National Engineering Laboratory for Modern Silk, Soochow

University, Suzhou 215123, Jiangsu, People's Republic of China also resulted in significantly lower remaining activity of the wild type AChE than that of the mutant AChE. These results indicated that mutations for the three amino acids reduced the sensitivity of AChE to physostigmine and phoxim, which laid the foundation for future in vivo studies on AChE's roles in pesticide resistance.

Keywords Bombyx mori - Acetylcholinesterase · Gene mutation

\section{Introduction}

Acetylcholinesterase (AChE, EC 3.1.1.7) is encoded by the acetylcholinesterase gene (ace), and it maintains the normal transmission of neural impulses in synaptic clefts through catalyzing the hydrolysis of neurotransmitter acetylcholine. $\mathrm{AChE}$ is the target enzyme for organophosphorus and carbamate pesticides [1]. These pesticides can bind to $\mathrm{AChE}$ and reduce its activity, leading to massive accumulation of postsynaptic membrane acetylcholine, continuous stimulation, biological convulsion and the eventual insect death.

The ace gene's overexpression and mutations are the main reason of pesticide resistance to organophosphate pesticides. Gao and Zhu found that increased transcription rates and/or stability of the mRNA resulted in elevated levels of AChE mRNA in OP-resistant clones of the greenbug (Schizaphis graminum) [2]; the pesticide resistance was increased by the loss of 3 or 5 glutamine residues on the C-terminus of AChE that increased GPI anchor efficiency to recruit more $\mathrm{AChE}$ on the plasma membrane. Increased number of GPI-anchored molecules in synaptic clefts may reduce their sensitivity to insecticides [3]. However, it is more widely believed that point mutations accompanied with the changes in kinetic parameters are the 
major reason of pesticide resistance [4-7]. Such resistancerelated point mutations include the substitutions of key sites in the activity region that have spatial effects, which may change the directivity of active site residues. Indeed, many potential point mutations in the ace gene have been shown to result in the resistance to organophosphorus pesticides $[8,9]$.

Cao et al. [10] found that the expression level of ace 2 was actually higher than that of ace 1 in $B$. mori cell lines. The ace 1 gene plays an important role in the cholinergic function and serves as the main target of anticholinesterase insecticides in insects [11]. Baek et al. [12] has reported that the organophosphate-resistant strain of Lepidoptera diamondback moth (Plutella xylostella) ace 1 possessed mutations for three amino acids (Ala201Ser, Gly227Ala, and Ala441Gly) in its conserved sequence, which may confer the moths their pesticide resistance. Amino acid sequence analysis revealed that the mutation of Ala441Gly also exists in the ace 1 gene in B. germanica; however, Kim et al. [13] reported that $B$. germanica was not resistant to organophosphorus pesticides. Therefore, this mutation may only play very limited role, if any, in pesticide resistance. Li et al. [14] discovered that the Leu452Ser mutation in the ace 1 gene is unique in the resistant strains of $P$. xylostella (ACCESSION: AY970293) by comparing the sequences of different insect ace $1 \mathrm{~s}$, suggesting important correlation between this site and insecticide resistance.

The silkworm (Bombyx mori) is an important economic insect and has also become an important model insect with its finished genomic maps and re-sequencing [15-17]. In 1999, Surendra Nath and Surendra Kumar [18] first used B. mori as a model to study the effects of organophosphate insecticides on AChE's activity and metabolic levels. In 2007, Seino et al. [19] first cloned and characterized the full length cDNA of the two ace genes in B. mori. Shang et al. [20] first expressed the B. mori $\mathrm{Bm}$-ace 1 and $\mathrm{Bm}-a c e 2$ in eukaryotic cells and demonstrated that the eukaryotic Bm-ace 2 was sensitive to organophosphorus pesticides. In 2009, Chen et al. [21] reported the activity of $B$. mori $\mathrm{AChE}$ and the transcript differences of ace 1 and ace 2 . Peng et al. [22] revealed the transcript level changes of ace genes induced by different doses of pesticides, indicating ace 1's important role in pesticide induction. However, no studies have been reported on the functional roles of the mutant sites in B. mori ace 1 on organophosphorus pesticide resistance.

\section{Materials and methods}

Materials and major reagents

Escherichia coli DH5 $\alpha$ and Top10 strains were maintained in our laboratory. The Bac to Bac expression system, Bacmid-containing E. coli strain Ac DH10Bac and the
pFastBac ${ }^{\mathrm{TM}}$ HT B plasmid were kindly provided by Professor Wenbing Wang at Jiangsu University. The $s f 9$ cells were subcultured in our laboratory.

The DNA polymerase, restriction endonucleases, T4 DNA ligase, and DNA marker were purchased from TaKaRa Biotechnology (Dalian) Co., Ltd. The Pfu DNA polymerase and protein prestained marker were purchased from Fermentas. PCR primers were synthesized in Shanghai Sangon Biological Engineering Technology \& Services Co., Ltd. The primary anti-His-tag antibody rabbit IgG and the secondary AP-labeled goat anti-rabbit IgG were purchased from Abcam Co., Ltd., UK and Santa Cruz Biotech, Inc, USA, respectively. AP Conjugate Substrate Kit (170-6432) was purchased from Bio-Rad Laboratories. Insect cell culture medium TC100 was purchased from Applichem. Fetal bovine serum (FBS) was purchased from Hyclone; and Celfectin transfection reagent and the Ni-NTA purification system were purchased from Invitrogen. The chemical Phoxim [O,O-Diethyl O-(alpha-cyanobenzylideneamino)phosphorothioate] was purchased from Sigma-Aldrich Company. The physostigmine was purchased from Tokyo Kasei Kogyo Co., Ltd. Other major reagents were purchased from Shanghai Sangon Biological Engineering Technology \& Services Co., Ltd.

\section{Methods}

\section{Ace1 cloning and site-directed mutagenesis}

Three pairs of mutagenesis primers were designed (Table 1) to amplify the PCR product containing Ala(GCG)303Ser(TCG), Gly(GGA)329Ala(GCA) and Leu (TCT)554Ser(TTC) mutation. The Ala303Ser mutation was gernerated by using pUCwace 1 plasmid as template, $\mathrm{F} 1$ and $\mathrm{R} 1$ as primers, and $P f u$ high fidelity enzyme as DNA polymerase. The PCR product was digested with $D p n$ I to eliminate the methylated DNA template but retain the mutant PCR product. Then the product was cloned into pUCmT vector and confirmed by sequencing. F2, R2; F3, R3 primers were used to further amplify the mutant fragment and confirmed by sequencing.

\section{Construction and identification of recombinant vector pFastBac ${ }^{T M}$ HT B-acel}

The ace1-XbaI and ace1-XhoI primers containing restriction endonuclease sites (Table 1) were designed to amplify the ace 1 fragment from pUC-wace 1 and pUC-mace1,

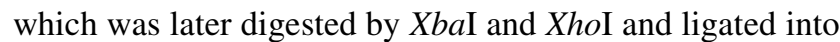
pFastBac ${ }^{\mathrm{TM}}$ HT B. After transformation into the E. coli DH5 $\alpha$ competent cells, positive recombinant plasmids pFastBac $^{\mathrm{TM}}$ HT B-wace 1 and pFastBac ${ }^{\mathrm{TM}}$ HT B-mace 1

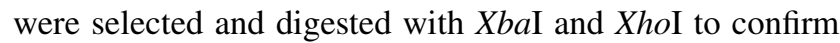
the correct insertion of $\mathrm{pFastBac}{ }^{\mathrm{TM}}$ HT B. 
Table 1 Primer sequences of PCR

\begin{tabular}{lll}
\hline The name of primer & Primer sequence & Length of product (bp) \\
\hline F1 & TTATTCGGTGAATCATCGGGAGCCGTGTCAG & 4,800 \\
R1 & CTGACACGGCTCCCGATGATTCACCGAATAA & \\
F2 & CTATCATGCAGTCTGCAGCCGCCACTGCTCC & 4,800 \\
R2 & GGAGCAGTGGCGGCTGCAGACTGCATGATAG & \\
F3 & GTTCGGGGAGCTTCCAATCCCGGGAAA & 4,800 \\
R3 & TTTCCCGGGATTGGAAGGCTCCCCGAAC & \\
ace 1 -Xba I & GCTCTAGAATGCGCGTGGTGTTGGCA & 2,100 \\
ace 1 -Xho I & CCGCTCGAGTTATATGGTGTATTTGAACAGTGC & \\
M13 forward & GTTTCCCAGTCACGAC & 4,530 \\
M13 reverse & CAGGAAACAGCTATGAC & \\
\hline
\end{tabular}

Construction and identification of recombinant baculovirus plasmids Bacmid-wacel and Bacmid-mace1

Recombinant plasmids pFastBac ${ }^{\mathrm{TM}}$ HT B-wace 1 and pFastBac $^{\text {TM }}$ HT B-mace 1 were extracted and transformed into E. coli Ac DH10Bac competent cells. Recombinant bacmids Bacmid-wace 1 and Bacmid-mace 1 were extracted by the alkali lysis method with blue colonies as negative controls. The upstream and downstream M13 primers were used to identify and screen for the targeting recombinant plasmids Bacmid-wace 1 and Bacmid-mace 1.

Transfection of recombinant baculovirus plasmids Bacmidwacel and Bacmid-macel into sf9 cells

The confirmed correct Bacmid-wace 1 and Bacmid-mace 1 plasmid DNA was transfected into $s f 9$ cells using Celfectin transfection reagent (Life Technologies) following the manufacturer's manual. After 3-4 days culture at $27{ }^{\circ} \mathrm{C}$, correct growth and morphology of cells were confirmed under an inverted microscope. The $s f 9$ cells transfected with wild type Bacmid and those without transfection were both used as negative controls. The supernatants of transfected cells were collected and saved at $4{ }^{\circ} \mathrm{C}$, and the pellets were centrifuged at $300 \mathrm{~g}$ for $5 \mathrm{~min}$ to remove cells and debris to obtain the passage 1 (P1) virus. P1 virus was used to re-infect the cells to obtain high titer recombinant virus solutions. The virus titer and the $50 \%$ tissue culture infective dose (TCID50 value, data not shown) were determined by using the end-point dilution method [23].

\section{Detection of recombinant virus expression}

The sf9 cells with $72 \mathrm{~h}$ Bacmid infection (Bacmid-wace 1 and Bacmid-mace 1) were collected along with the negative control cells for SDS-PAGE. SDS-PAGE was performed using electrophoresis cells from Bio-Rad; the separating gel contained $12 \%$ acrylamide, and the stacking gel contained $5 \%$ acrylamide. Routinely, the gels were stained for proteins with Coomassie brilliant blue R250. After proteins were transferred from gels $(120 \mathrm{~min}, 70 \mathrm{~V})$ to PVDF membranes (Millipore, USA)by tank Blotting, the membranes were blocked for $1 \mathrm{~h}$ with a $5 \%$ skim milk/TBST solution (0.02 M Tris, $0.15 \mathrm{M} \mathrm{NaCl}, 0.1 \%$ Tween $20, \mathrm{pH}$ 7.5) at $4{ }^{\circ} \mathrm{C}$ and then incubated with anti-His-tag antibody (diluted 1:5, 000) for $1 \mathrm{~h}$ at room temperature. After washing in TBST for $15 \mathrm{~min}$ for three times, the membranes were incubated for $1 \mathrm{~h}$ at room temperature with a goat anti rabbit IgG-AP (diluted 1:10, 000 in skim milk/ TBST solution). After washing in TBST for $15 \mathrm{~min}$ for three times, the blots were stained with the AP Conjugate Substrate Kit following the kit protocol. Then the proteins were purified with the Ni-NTA purification system following the user manual.

\section{Biological activity analysis}

The activity assay was evaluated using the method of Ellman et al. [24] with some modifications. The reaction was carried out in 96-well microtiter plates. In detail, the activity of $\mathrm{AChE}$ was determined by the acetylcholinesterase measurement kit following the manufacturer's manual (Nanjing Technology Co., Ltd.). The Substrate buffer was ATC (acetylthiocholine iodide) with different concentrations from 0.05 to $10 \mathrm{mM}$. Four groups of samples were used in the measurement procedure: the blank control group, the standard control group, the experimental control group and the experimental group. The volume of each component was following Table 2. All components were mixed and incubated for $10 \mathrm{~min}$ for measurements at $412 \mathrm{~nm}$ in 0.5 optical path. The activity of $\mathrm{AChE}=[$ (experimental group experimental control) $\times \mathrm{AChE}$ standard concentration]/ [(standard control- blank control) $\times$ Experimental sample concentration]. Three biological replicates were used in each group. The signals were read with a Multiskan GO microplate reader (Model5111 9200; Thermo Scientific, Nanjing, China) at $412 \mathrm{~nm}$, with one reading per $30 \mathrm{~s}$. The reaction was at $30^{\circ} \mathrm{C}$, and 10 values were recorded for each reaction. 
Table 2 The volume of each component in activity detection

\begin{tabular}{lcccc}
\hline & $\begin{array}{l}\text { Experimental } \\
\text { group }\end{array}$ & $\begin{array}{l}\text { Experimental } \\
\text { control }\end{array}$ & $\begin{array}{l}\text { Standard } \\
\text { control }\end{array}$ & $\begin{array}{l}\text { Blank } \\
\text { control }\end{array}$ \\
\hline Experimental sample $(\mu \mathrm{L})$ & 10 & - & - & - \\
$\quad$ AChE standard $(\mu \mathrm{L})$ & - & - & 10 & - \\
Double distilled water $(\mu \mathrm{L})$ & - & - & - & 10 \\
Substrate buffer $(\mu \mathrm{L})$ & 100 & 100 & 100 & 100 \\
Color developing agent & 100 & 100 & 100 & \\
$\quad(\mu \mathrm{L})$ & & & & 6 \\
Mixed and incubated at $37{ }^{\circ} \mathrm{C}$ for 6 min & 6 & 6 & 6 & 20 \\
Inhibitor $(\mu \mathrm{L})$ & 6 & 20 & 20 & 10 \\
Transparent agent $(\mu \mathrm{L})$ & 20 & 10 & 10 & - \\
Stabilizer $(\mu \mathrm{L})$ & 10 & 10 & - & \\
Sample $(\mu \mathrm{L})$ & - & & & \\
\hline
\end{tabular}

The data were recorded and processed with the Skanit software (Thermo Scientific), and the values of $\mathrm{Km}$ and Vmax were calculated by using the Lineweaver-Burk plots method.

In the detection of remaining activity, $10 \mu \mathrm{L}$ enzyme solution was mixed with $10 \mu \mathrm{L}$ physostigmine or phoxim solution at different concentrations in microtiter plates and settled at $37{ }^{\circ} \mathrm{C}$ for $10 \mathrm{~min}$ for complete binding of the enzyme and its inhibitor. Water was used as control. The remaining activity of $\mathrm{AChE}$ was then determined by using the acetylcholinesterase measurement kit following the manufacturer's manual (Nanjing Technology Co., Ltd.). Three biological replicates were used in each group.

\section{Statistical Analysis}

All results are expressed as mean \pm standard error (SE). The significant differences were examined by unpaired Student's $t$ test using SPSS 19 software (USA). A $p$-value $<0.05$ was considered as statistically significant.

\section{Results}

\section{Directed mutagenesis}

With plasmid pUC-wace 1 as template, the mutant plasmid was generated by directed mutagenesis PCR, digested with $D p n I$ to eliminate the template, and transformed into E. coli DH5 $\alpha$ competent cells. The positive colonies were picked and the plasmid DNA was amplified for sequencing. As shown in Fig. 1, the $\mathrm{G}$ at position 907 was mutated into $\mathrm{T}$, the $\mathrm{G}$ at position 986 was mutated into $\mathrm{C}$, and the $\mathrm{C}-\mathrm{T}$ at positions 1, 660 and 1, 661 were mutated into T-C, which resulted in the amino acid changes of Ala303Ser, Gly329Ala and Leu554Ser.
Construction and identification of $\mathrm{pFastBac}^{\mathrm{TM}} \mathrm{HT}$ B-wace 1 and pFastBac ${ }^{\text {TM }}$ HT B-mace 1

The size of the ace 1 gene is 2, $100 \mathrm{bp}$. As shown in Fig. 2, fragments with expected size of the ace 1 gene from PCR amplification with pUC-wace 1 and pUC-mace 1 as templates were observed after $X b a \mathrm{I}$ and $X h o I$ digestion. The size of the donor plasmid pFastBac ${ }^{\mathrm{TM}}$ HT B is $4.8 \mathrm{~kb}$. As shown in Fig. 3, a band with expected size of about 2, $100 \mathrm{bp}$ was observed from the XbaI and XhoI digestion of the recombinant plasmids pFastBac ${ }^{\mathrm{TM}} \mathrm{HT}$ B-wace 1 and $\mathrm{pFastBac}{ }^{\mathrm{TM}} \mathrm{HT}$ B-mace1, demonstrating the successful construction of pFastBac $^{\text {TM }}$ HT B-ace 1 .

PCR identification of the recombinant baculovirus Bacmid-ace 1

Using the recombinant baculovirus plasmids Bacmidwace 1 and Bacmid-mace 1 as templates, the targeting gene of ace 1 with the size of 2, $100 \mathrm{bp}$ was PCR amplified with the primer pair of M13 forward/M13 reverse; the successfully transposed Bacmid with the size of 4, $500 \mathrm{bp}$ was PCR amplified with the primer pair of M13 forward/M13 reverse, while the PCR product for the Bacmid without transposition was only $300 \mathrm{bp}$. As shown in Fig. 4, expected sizes of PCR products were obtained, demonstrating the successful transposition of the ace 1 gene.

Transfection of recombinant baculovirus plasmids Bacmid-wace 1 and Bacmid-mace 1 into $s f 9$ cells

The identified recombinant baculovirus plasmids Bacmidwace 1 and Bacmid- mace 1 were transfected into sf9 cells in logarithmic phase. 7 days after transfection, the cells were observed under an inverted microscope, which 

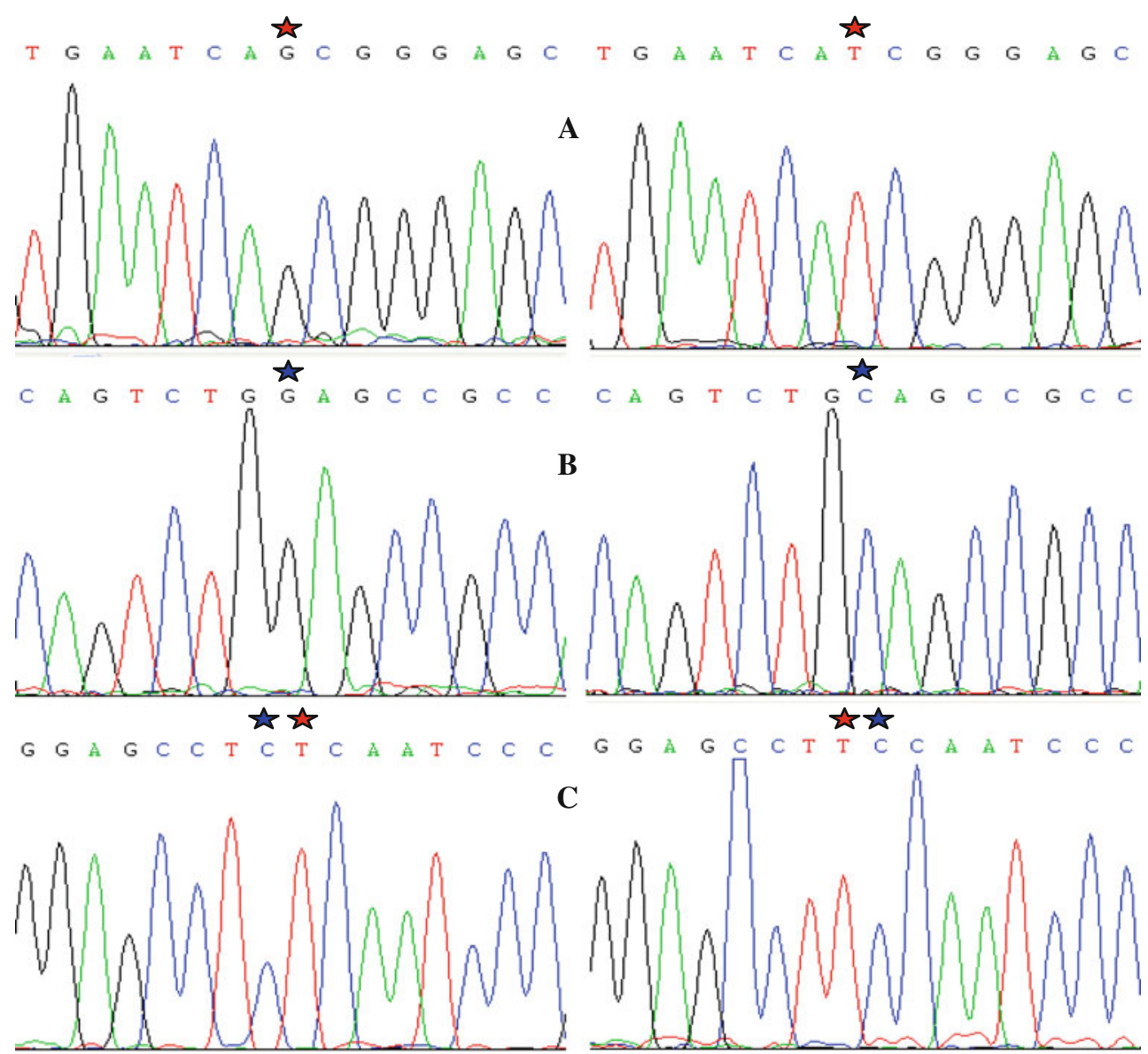

Fig. 1 Sequencing figure of the wace 1 and mace 1 ( $A, B, C$ indicates the mutation site, and the asterisk indicates the mutation bases sites)

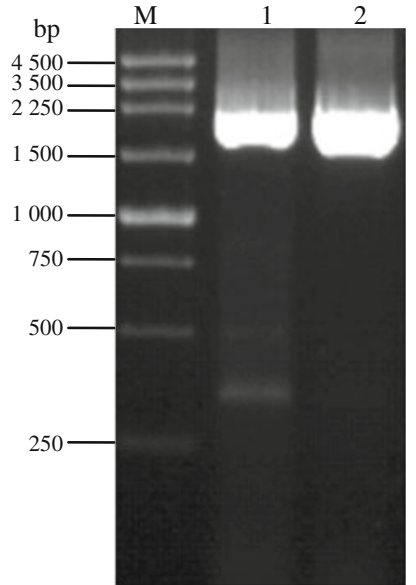

Fig. 2 PCR results of wild type and mutant acetylcholinesterase genes M. $250 \mathrm{bp}$ DNA marker 1 PCR product of wace 12 PCR product of mace 1

revealed significantly changes that included round shapes, enlarged nucleoli, the formation of intracellular vesicles and apoptotic bodies, and cell detachment and suspension (Fig. 5). The viral supernatants were collected and saved

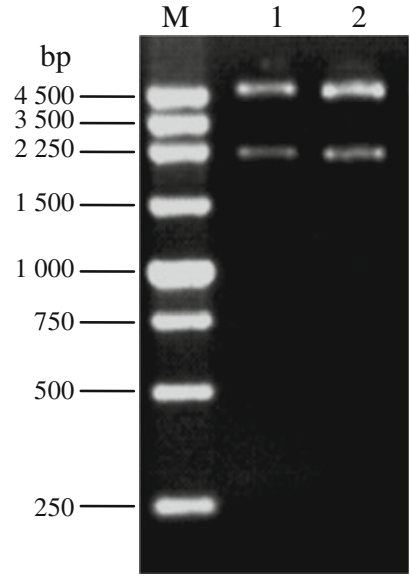

Fig. 3 Verification of recombinant plasmid pFastBac ${ }^{\mathrm{TM}} \mathrm{HT}$ B-ace 1 by enzyme digestion M. 250 bp DNA marker 1 pFastBac HT B-mace 1 recombinant plasmid digested with Xba I and Xho I 2 pFastBac $^{\text {TM }}$ HT B-wace 1 recombinant plasmid digested with Xba I and Xho I

for re-inoculation. The $s f 9$ cells were infected with the P3 virus, and the cells displayed apparent pathological symptoms $72 \mathrm{~h}$ later. 


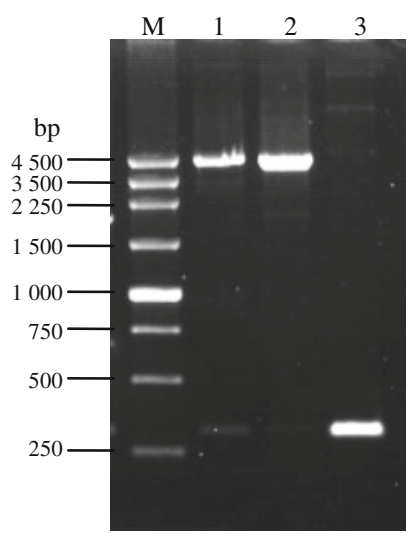

Fig. 4 Verification of recombinant Bacmid-ace 1 by PCR M. 250 bp DNA marker 1 PCR product of Bacmid- wace 12 PCR product of Bacmid- -mace 13 PCR product of the empty bacmid

Product detection of recombinant virus expression

Sf9 cells were infected with the $\mathrm{P} 3$ recombinant viruses Bacmid-wace 1 and Bacmid-mace $1\left(5 \times 10^{5}\right.$ cells/well $)$ with empty virus as negative control. The cells were collected after $72 \mathrm{~h}$ culture for SDS-PAGE and Westernblotting analyses. As shown in Fig. 6, an expected specific band with the size of about $76 \mathrm{kDa}$ was observed, demonstrating correct expression of the targeted protein. Approximately $0.53 \mathrm{mg}$ of purified AChE was obtained from $100 \mathrm{~mL}$ culture solution, and SDS-PAGE analysis revealed only one band for the purified enzyme (Fig. 7), demonstrating sufficiently high purity of the purified AChE for further experiments.

Biological activity of the expression product

Recombinant AChE expressed in the baculovirus system was used for biochemical characterization. Biochemical kinetic assays (Fig. 8) revealed that the $\mathrm{Km}$ of $\mathrm{wAChE}$ and $\mathrm{mAChE}$ was $0.0305 \mathrm{mM}$ and $0.0284 \mathrm{mM}$ for acetylthiocholine, respectively, with the Vmax values of 0.731 and $0.743 \mu \mathrm{M} \mathrm{min}{ }^{-1} \mathrm{mg}^{-1}$, respectively, demonstrating the preference for acetylthiocholine substrates. These results indicate that the two enzymes have similar kinetic properties.

The inhibition of the two AChEs by physostigmine and phoxim was investigated to reveal the effects of mutations on the enzymic activity. When the physostigmine concentration reached $10 \mu \mathrm{M}$, the relative remain activity of the wild-type AChE was $13.84 \pm 0.56 \%$, only $75.41 \%$ of that of the mutant $\mathrm{AChE}$ at $18.35 \pm 0.71 \%$, indicating higher
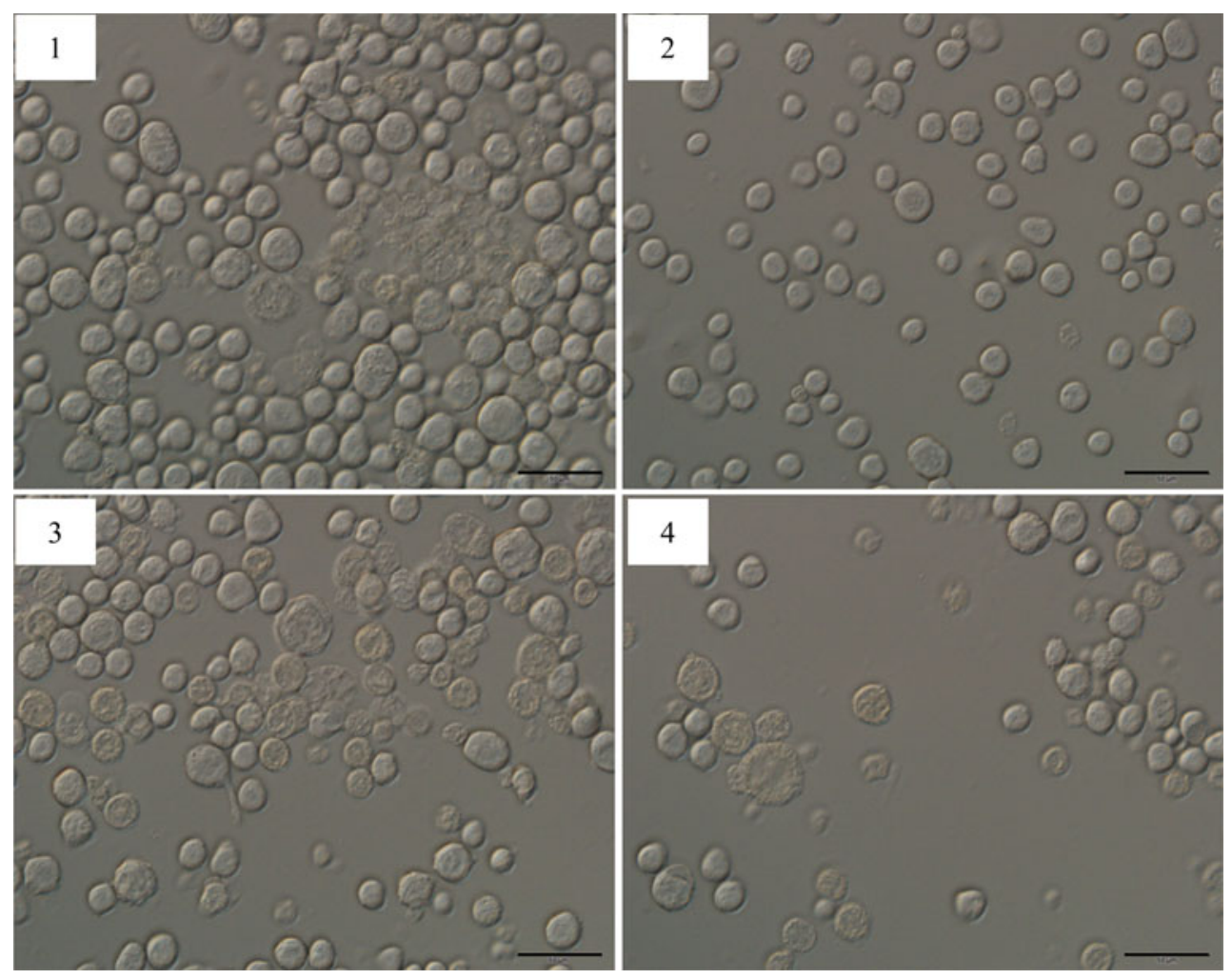

Fig. 5 Phenotype of $s f 9$ cells transfected with recombinant Bacmidwacel and Bacmid-macel under microscope (scale bars represent $50 \mu \mathrm{m}) .1$ Cells transfected with recombinant Bacmid-wace 1; 2 sf9 cells; 3 cells transfected with recombinant Bacmid-mace $1 ; 4$ cells transfected with empty Bacmid. $s f 9$ cells and cells transfected with empty Bacmid were used as controls 


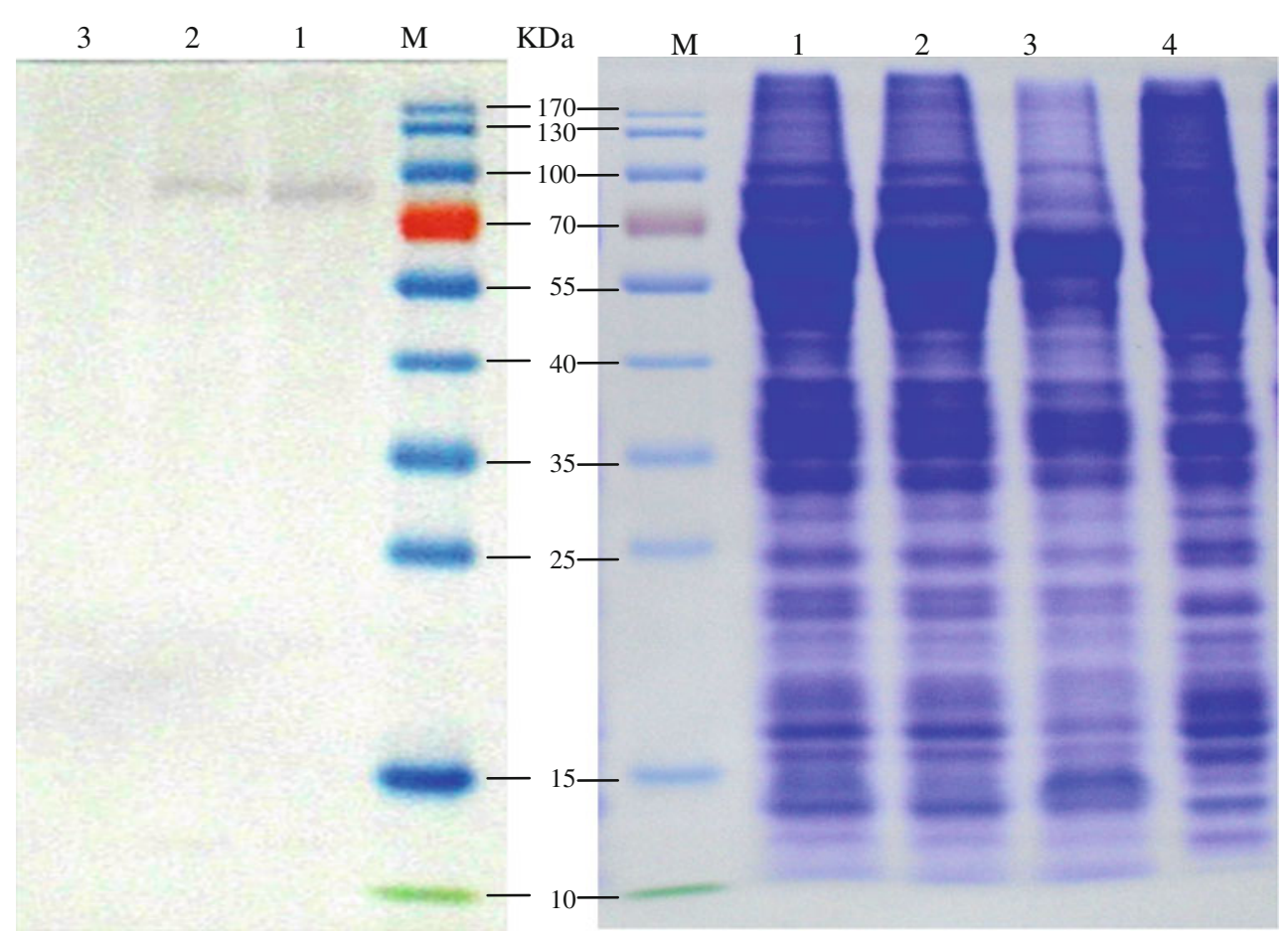

Fig. 6 Analysis of recombinant ace1 expressed in $s f 9$ cells : the left picture was the western blotting results of cells transfected with empty Bacmid, mace 1 and wace 1 ; the right picture was the SDS-

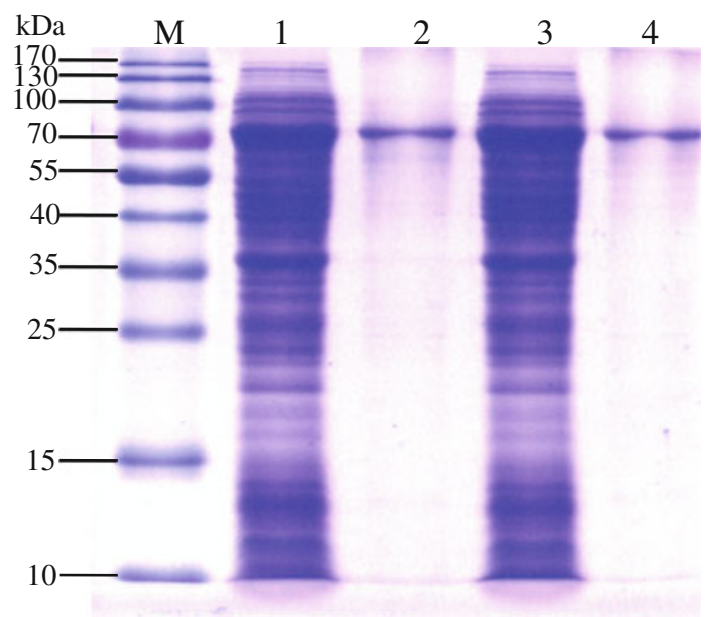

Fig. 7 Expression of the Bmace 1 in $s f 9$ and purification $M$ prestained protein ladder, 1 mace 1 expression product, 2 purification product of mace 1 expression product, 3 wace 1 expression product, 4 purification product of wace 1 expression product

sensitivity of the wild type AChE to acetylcholinesterase inhibitors (Fig. 9). After being treated with $33.4 \mu \mathrm{M}$ phoxim, the mutant AChE's relative remain activity was $14.09 \pm 0.53 \%$, about 1.40 times of the wild type AChE's activity at only $10.06 \pm 0.35 \%$, indicating that the wild type $\mathrm{AChE}$ is more sensitive to organophosphorus insecticides and that the mutant $\mathrm{AChE}$ has weaker binding ability to phoxim (Fig. 9).
PAGE of expression product ( $M$ prestained protein ladder, $1-4$ mace 1 expression product, wace 1 expression product, control bacmid expression product, and $s f 9$ cell expression product, respectively.)

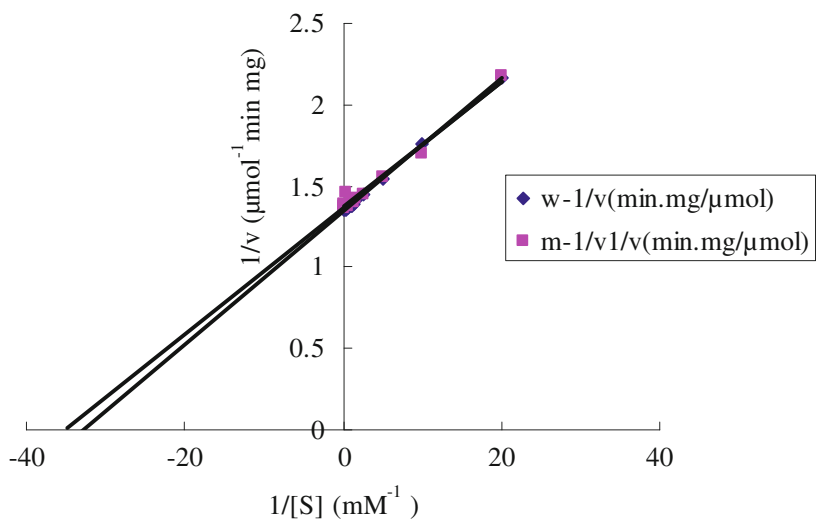

Fig. 8 Lineweaver-Burk double-reciprocal plot of AChE activity for substrates acetylthiocholine $(\mathrm{ATCh}(\mathrm{X}$ intercept $=-1 / \mathrm{Km}$; Y intercept $=1 / \mathrm{Vmax} ;$ Slope $=\mathrm{Km} / \mathrm{Vmax})$

\section{Discussion}

Relationship between ace 1 function and mutations

Lepidopteran insects have two AChEs, the two enzymes have distinct catalytic properties and responses to different inhibitors, AChE1 is more sensitive than AChE2 to most OP insecticides[25].In this study, we generated mutations for three amino acids in AChE1, the site of Ala303 is located in the cholinesterase activity center (FGESAG) and close to the catalytic triad Ser302. Mutations were also 


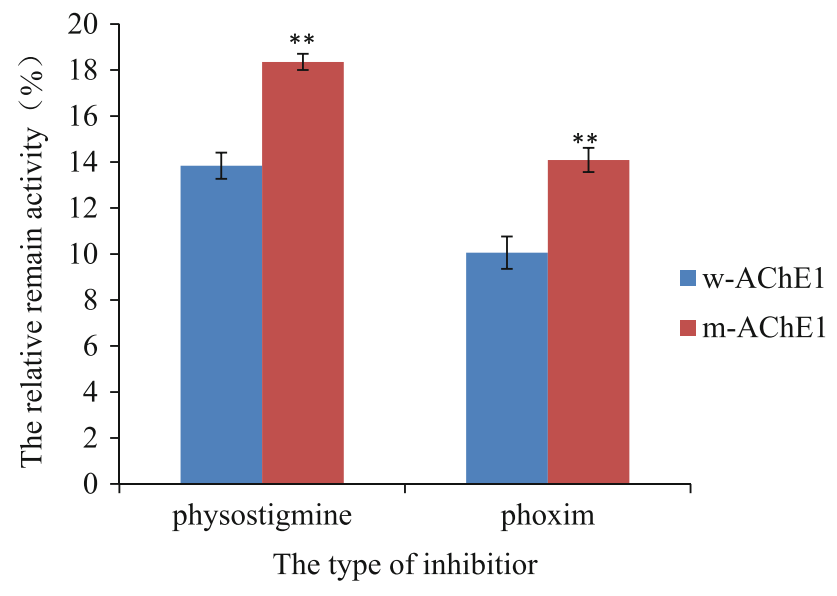

Fig. 9 Inhibition plot for $\mathrm{AChE}$ activity with physostigmine and phoxim. (the physostigmine concentration was $10 \mu \mathrm{M}$; The phoxim concentration was $33.4 \mu \mathrm{M})$. Bars marked with double asterisks means it is significantly different from the w-AChE1. $(p<0.05)$

discovered in similar region (Ala201Ser) in the resistant strains of diamondback moth [12], indicating that mutations in this site may affect the function of acetylcholinesterase. Other mutations, such as Gly303Ala and Gly262Ala, may be related to organophosphorus pesticide resistance in Drosophila melanogaster and Musca domestica, respectively [7, 26]. The Drosophila Gly303 that corresponds to the B. mori Gly329 has been reported to affect the orientation of Ser276, which is phosphorylated or arbamoylated by insecticides [7]. The Leu554 is located in the conserved region of AChE and is changed to Ser in the resistant strains of Diamondback moth. The findings in this study demonstrate the important roles of the three point mutations in the function of the B. mori AChE.

\section{Interaction among mutation sites}

It has been reported that either Gly228Ser or Phe439Trp mutation in Tetranychus urticae increased the insensitivity of insects by 26 or 99 times, respectively, while double mutations were able to increase the insensitivity by 1165 times. The Ala391Thr mutation alone did not change the dynamics, although it did inhibit the effects of Phe439Trp mutation [27], indicating an interaction between different ace mutations. In this study, the activity difference between the wild type and mutant AChEs was not significant, suggesting that the interactions among the three mutations may affect the enzymic activity. Further investigations are needed to explore the specific synergy or antagonism among the three mutations.

Functional study of the B. mori ace 1 mutations

In recent years, the resistance of Lepidopteran insects to chemical pesticides has increased gradually with their widespread use in agriculture and forestry and has been the focus in the research of pest control. On the other hand, the $B$. mori is an important economic Lepidopteran insect with low resistance to chemical pesticides because of long-term indoor domestication. Therefore, chemical pesticide contamination has become a serious problem for the sericulture in China [28]. In this study, we constructed plasmids containing different mutant sites of the ace gene, based on the discoveries from the resistant Diamondback moth. The mutant AChE was expressed using the baculovirus expression system. The expressed protein was purified and inhibited by physostigmine and phoxim to measure the remaining enzyme activity. The mutant AChE showed significantly higher remaining enzyme activity than the wild-type, indicating the close relationship between the mutated sites and AChE's sensitivity to physostigmine and phoxim. Due to the complexity of the metabolic resistance at organismic level, further investigations are clearly required to confirm the findings on the pesticide resistance in vivo.

Acknowledgments This work was supported by the National High Technology Research and Development Program of China (863 Program) (Grant No. 2013AA102507), the transformation project of agriculture scientific and technological achievements (2013GB2C100180), the projects sponsored by the national cocoons silk development funds in 2013, the Priority Academic Program Development of Jiangsu Higher Education Institutions, the National Natural Science Foundation of China (Project: 31072086), the China Agriculture Research System (CARS-22-ZJ0305).

Open Access This article is distributed under the terms of the Creative Commons Attribution License which permits any use, distribution, and reproduction in any medium, provided the original author(s) and the source are credited.

\section{References}

1. Lang GJ, Shang JY, Chen YX, Cui YC, Wang Q, Tang ZH, Zhang CX (2010) Expression of the housefly acetylcholinesterase in a bioreactor and its potential application in the detection of pesticide residues. World J Microbiol Biotechnol 26(10): $1795-1801$

2. Gao JR, Zhu KY (2002) Increased expression of an acetylcholinesterase gene may confer organophosphate resistance in the greenbug, Schizaphis graminum (Homoptera: Aphididae). Pestic Biochem Phys 73(3):164-173

3. Kakani EG, Bon S, Massoulié J, Mathiopoulos KD (2011) Altered GPI modification of insect AChE improves tolerance to organophosphate insecticides. Insect Biochem Mol Biol 41(3): $150-158$

4. Walsh SB, Dolden TA, Moores GD, Kristensen M, Lewis T, Devonshire AL, Williamson MS (2001) Identification and characterization of mutations in housefly (Musca domestica) acetylcholinesterase involved in insecticide resistance. Biochem $\mathrm{J}$ 359(Pt 1):175-181

5. Zhu KY, Lee SH, Clark JM (1996) A point mutation of acetylcholinesterase associated with azinphosmethyl resistance and reduced fitness in Colorado potato beetle. Pestic Biochem Physiol 55(2):100-108 
6. Temeyer KB, Brake DK, Schlechte KG (2012) Acetylcholinesterase of Haematobia irritans (Diptera: Muscidae): baculovirus expression, biochemical properties, and organophosphate insensitivity of the G262A mutant. J Med Entomol 49(3):589-594

7. Mutero A, Pralavorio M, Bride JM, Fournier D (1994) Resistance-associated point mutations in insecticide-insensitive acetylcholinesterase. Proc Natl Acad Sci USA 91(13):5922-5926

8. Vaughan A, Rocheleau T, Ffrench-Constant R (1997) Sitedirected mutagenesis of an acetylcholinesterase gene from the yellow fever mosquitoaedes aegypticonfers insecticide insensitivity. Exp Parasitol 87(3):237-244

9. Chen Z, Newcomb R, Forbes E, McKenzie J, Batterham P (2001) The acetylcholinesterase gene and organophosphorus resistance in the Australian sheep blowfly, Lucilia cuprina. Insect Biochem Mol Biol 31(8):805-816

10. Cao YQ, Liu LH, Wang JM, Wang YH, Shen WD, Li B (2012) Functional study of acetylcholinesterase genes in Bombyx mori ovary cells using RNA interference. Entomol Exp Appl 142(2):140-144

11. Lu YH, Park Y, Gao XW, Zhang X, Yao JX, Pang YP, Jiang HB, Zhu KY (2012) Cholinergic and non-cholinergic functions of two acetylcholinesterase genes revealed by gene-silencing in Tribolium castaneum. Sci Rep 2:288

12. Baek JH, Kim JI, Lee DW, Chung BK, Miyata T, Lee SH (2005) Identification and characterization of ace1-type acetylcholinesterase likely associated with organophosphate resistance in $\mathrm{Plu}$ tella xylostella. Pestic Biochem Phys 81(3):164-175

13. Kim JI, Jung CS, Koh YH, Lee SH (2006) Molecular, biochemical and histochemical characterization of two acetylcholinesterase cDNAs from the German cockroach Blattella germanica. Insect Mol Biol 15(4):513-522

14. Li B, Wang YH, Liu HT, Xu YX, Wei ZG, Chen YH, Shen WD (2010) Genotyping of acetylcholinesterase in insects. Pestic Biochem Phys 98(1):19-25

15. Xia QY, Zhou ZY, Lu C, Cheng DJ, Dai FY, Li B, Zhao P, Zha XF, Cheng TC, Chai CL, Pan GQ, Xu JS, Liu C, Lin Y, Qian JF, Hou Y, Wu ZL, Li GR, Pan MH, Shen YH, Lan XQ, Yuan LW, Li T, Xu HF, Yang GW, Wan YJ, Zhu Y, Yu MD, Shen WD, Wu DY, Xiang ZH, Yu J, Wang J, Li RQ, Shi JP, Li H, Li GY, Su JN, Wang XL, Li GL, Zhang ZJ, Wu QF, Li J, Zhang QP, Wei N, Xu JZ, Sun HB, Dong L, Liu DY, Zhao SL, Zhao XL, Meng QS, Lan FD, Huang XG, Li YZ, Fang L, Li CF, Li DW, Sun YQ, Zhang ZP, Yang Z, Huang YQ, Xi Y, Qi QQ, He DD, Huang HY, Zhang XW, Wang ZQ, Li WJ, Cao YZ, Yu YP, Yu H, Li JH, Ye JH, Chen H, Zhou Y, Liu B, Wang J, Ye J, Ji H, Li ST, Ni PX, Zhang JG, Zhang Y, Zheng HK, Mao BY, Wang W, Ye C, Li SG, Wang J, Shu Wong GK, Yang HM (2004) A draft sequence for the genome of the domesticated silkworm (Bombyx mori). Science 306(5703): 1937-1940

16. Consortium TISG (2008) The genome of a lepidopteran model insect, the silkworm Bombyx mori. Insect Biochem Mol Biol 38(12):1036-1045
17. Xia QY, Guo YR, Zhang Z, Li D, Xuan ZL, Li Z, Dai FY, Li YR, Cheng DJ, Li RQ, Cheng TC, Jiang T, Becquet CL, Xu X, Liu C, Zha XF, Fan W, Lin Y, Shen YH, Jiang L, Jensen J, Hellmann I, Tang S, Zhao P, Xu HF, Yu C, Zhang GJ, Li J, Cao JJ, Liu SP, He NJ, Zhou Y, Liu H, Zhao J, Ye C, Du ZH, Pan GQ, Zhao AC, Shao HJ, Zeng W, Wu P, Li CF, Pan MH, Li JJ, Yin XY, Li DW, Wang J, Zheng HS, Wang W, Zhang XQ, Li SG, Yang HM, Lu C, Nielsen R, Zhou ZY, Wang J, Xiang ZH, Wang J (2009) Complete resequencing of 40 genomes reveals domestication events and genes in silkworm (Bombyx). Science 326(5951):433-436

18. Surendra Nath B, Surendra Kumar RP (1999) Toxic impact of organophosphorus insecticides on acetylcholinesterase activity in the silkworm, Bombyx mori L. Ecotox Environ Safe 42(2):157-162

19. Seino A, Kazuma T, Tan AJ, Tanaka H, Kono Y, Mita K, Shiotsuki T (2007) Analysis of two acetylcholinesterase genes in Bombyx mori. Pestic Biochem Phys 88(1):92-101

20. Shang JY, Shao YM, Lang GJ, Yuan G, Tang ZH, Zhang CX (2007) Expression of two types of acetylcholinesterase gene from the silkworm, Bombyx mori, in insect cells. Insect Sci 14(6):443-449

21. Chen HJ, Liao Z, Hui XM, Li GQ, Li F, Han ZJ (2009) Ace2, rather than ace1, is the major acetylcholinesterase in the silkworm, Bombyx mori. Insect Sci 16(4):297-303

22. Peng GD, Wang JM, Ma L, Wang YH, Cao YQ, Shen WD, Li B (2011) Transcriptional characteristics of acetylcholinesterase genes in domestic silkworms (Bombyx mori) exposed to phoxim. Pestic Biochem Phys 101(3):154-158

23. Huang S, Yu MS (2007) Research progress of baculovirus titer measurement method Prog in. Microbiol Immunol 35(2):79-83

24. Ellman GL, Courtney KD, Andres VJ, Feather Stone RM (1961) A new and rapid colorimetric determination of acetylcholinesterase activity. Biochem Pharmacol 7:88-95

25. Lang GJ, Zhang XH, Zhang MY, Zhang CX (2010) Comparison of catalytic properties and inhibition kinetics of two acetylcholinesterases from a lepidopteran insect. Pestic Biochem Phys 98(2): 175-182

26. Walsh SB, Dolden TA, Moores GD, Kristensen M, Lewis T, Devonshire AL, Williamson MS (2001) Identification and characterization of mutations in housefly (Musca domestica) acetylcholinesterase involved in insecticide resistance. Biochem $\mathrm{J}$ 359:175-181

27. Kwon DH, Choi JY, Je YH, Lee SH (2012) The overexpression of acetylcholinesterase compensates for the reduced catalytic activity caused by resistance-conferring mutations in Tetranychus urticae. Insect Biochem Mol Biol 42(3):212-219

28. Li B, Wang D, Zhao HQ, Shen WD (2010) Comparative analysis of two acetylcholinesterase genes of Bombyx mandarina and Bombyx mori. Afr J Biotechnol 9(49):8477-8485 